\title{
ChemComm
}

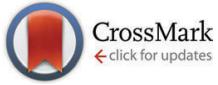

Cite this: Chem. Commun., 2015, 51, 13534

Received 30th June 2015, Accepted 9th July 2015

DOI: $10.1039 / \mathrm{c5cc05352h}$

www.rsc.org/chemcomm

\section{Photophysical efficiency-boost of aqueous aluminium phthalocyanine by hybrid formation with nano-clays $\dagger$}

\author{
Mark C. Staniford, ${ }^{a}$ Marina M. Lezhnina, $\ddagger^{*^{a}}$ Malte Gruener, ${ }^{\mathrm{b}}$ Linda Stegemann, ${ }^{\mathrm{b}}$ \\ Rauni Kuczius, ${ }^{c}$ Vera Bleicher, ${ }^{c}$ Cristian A. Strassert ${ }^{b}$ and Ulrich H. Kynast ${ }^{\star a}$
}

\begin{abstract}
Novel organic-inorganic hybrid materials comprising nanoscaled layered silicates and native aluminium hydroxide phthalocyanine $(\mathrm{Al}(\mathrm{OH}) \mathrm{Pc})$ allowed for the first time the exploitation of their unique photophysical properties in aqueous ambience. In particular, we were able to observe the efficient emission of $\mathrm{Al}(\mathrm{OH}) \mathrm{Pc}-$ nanoclay hybrids and generation of singlet oxygen in aqueous solution.
\end{abstract}

Since their serendipitous discovery just over a century ago, the structural and chemical as well as (photo-)physical properties of phthalocyanines (Pcs) have intrigued both, numerous researchers and entrepreneurs. This holds true for Pc-complexes with transition metals such as copper(II) phthalocyanines (CuPcs), which are nowadays extensively used as extraordinarily stable organic colour pigments and produced in excess of approximately 50000 tons annually, ${ }^{1}$ the most prominent blue pigment (C.I. Pigment Blue 15) being among them. Just as groundbreaking was the discovery of cell cytotoxicity exerted by metallo-porphyrins, the natural counterpart of Pcs, some sixty years ago, ${ }^{2}$ which stimulated a tremendous research effort on more stable, closed shell metal phthalocyanines like $\mathrm{ZnPc}, \mathrm{Al}(\mathrm{OH}) \mathrm{Pc}$ or $\mathrm{Si}(\mathrm{OH})_{2} \mathrm{Pc}$, and numerous others as well, due to their capability of photocatalysing the generation of singlet oxygen $\left({ }^{1} \mathrm{O}_{2}\right)$ via a triplet mechanism, ${ }^{3}$ this in turn providing a key step in photodynamic therapies (PDT) for cancer treatment. ${ }^{4}$ Further motivation is owed to the increasing antibiotic resistance amongst pathogenic bacteria, e.g. methicillin resistant Staphylococcus aureus ("MRSA"), against which photodynamic antimicrobial chemotherapy (PACT) promises

\footnotetext{
${ }^{a}$ Münster University of Applied Sciences, Institute for Optical Technologies, Stegerwaldstr. 39, 48565 Steinfurt, Germany. E-mail: uk@fh-muenster.de; Fax: +49-(0)2551-962187; Tel: +49-(0)2551-962119

${ }^{b}$ Westfälische Wilhelms-Universität Münster, Institute of Physics - Center for

Nanotechnology, Heisenbergstr 11, 48149 Münster, Germany.

E-mail: ca.s@wwu.de; Tel: +49-(0)251-5340-6102

${ }^{c}$ Mikrobiologisches Labor Dr. Michael Lohmeyer GmbH, Technologiehof Münster, Mendelstraße 11, 48149 Münster, Germany

$\dagger$ Electronic supplementary information (ESI) available: Experimental procedures, details of optical measurements, details of preliminary PACT experiments, additional Fig. S1-S10. See DOI: 10.1039/c5cc05352h

\# On leave from Volga State University of Technology, Institute of Physics, Lenin sq. 3, 424000 Yoshkar-Ola, Russia.
}

to provide an elegant treatment (see below); ${ }^{5}$ furthermore, fungi and biofilms may also be tackled. ${ }^{6}$ Unfortunately, unsubstituted metal phthalocyanines not only suffer from insolubility, but also tend to dimerise or aggregate in aqueous ambience, thereby losing their efficiency, which is obviously undesirable for biological matter as well. Enormous preparative effort has thus been invested for circumventing solubility and aggregation issues, such as the equipment of the Pc's periphery with ionizable (e.g. sulfonates, carboxylates, quaternary ammonium group) or mediating (e.g. polyether, glycol) substituents for improved solubility and with bulky ligands (e.g. $t$-butyl, $t$-butylphenyl) to prevent aggregation, ${ }^{3,4 c, 7}$ or both. ${ }^{8}$

Other strategies to increase the water solubility involve the use of carriers like (functionalised) gold nanoparticles, cyclodextrins and zeolites. ${ }^{9}$ In the case of $\mathrm{Al}(\mathrm{OH}) \mathrm{Pc}-$ gold nanoparticle conjugation, albeit not in water, an increase of the ${ }^{1} \mathrm{O}_{2}$ generation rate has just been reported. ${ }^{10}$ Very recently, pristine ZnPc and a very bulky, anionic ZnPc with 4-sulfonatophenoxyl substituents have been found to intercalate into the interlayers of layered double hydroxide stacks and to maintain high ${ }^{1} \mathrm{O}_{2}$-activity in the corresponding suspensions of the powders. ${ }^{11}$ However, ideal solutions remain yet to be realised.

In recent investigations, we have been able to demonstrate a surprising solubilisation of even neutral, natively insoluble dyes and complexes yielding completely transparent aqueous phases by the employment of nano-sized clays as shuttles, the assortment of dyes including Indigo, Nile Red, Coumarin 153 and even CuPc. ${ }^{12}$ The nano-clay employed was a commercially available, synthetic hectorite derivative (LAPONITE ${ }^{\mathbb{R}} \quad \mathrm{RD}, \S \quad \mathrm{Na}_{0.7}\left(\mathrm{H}_{2} \mathrm{O}\right)_{n}\left\{\left(\mathrm{Li}_{0.3} \mathrm{Mg}_{5.5}\right)^{-}\right.$ $\left.\left[\mathrm{Si}_{8} \mathrm{O}_{20}(\mathrm{OH})_{4}\right]\right\}$, "LAP"). ${ }^{13}$ LAP consists of anisotropic clay platelets with $25 \mathrm{~nm}$ diameter and a thickness of $1 \mathrm{~nm}$, which form stable and completely transparent dispersions in water due to the release of intercalated cations and consecutive exfoliation into highly charged individual platelets. According to the supplier ${ }^{13}$ and underlined by several studies, ${ }^{14,15}$ a single LAP disc possesses a diameter of $25 \mathrm{~nm}$ resulting in an area of $981.6 \mathrm{~nm}^{2}$ (Fig. 1; for a more detailed description of the LAPONITE ${ }^{\mathbb{R} \text {, }}$ s composition and cation exchange refer to the ESI $\dagger$ ). Although aiming at the mimicry of natural photosynthesis, i.e. electron transfer rather than ${ }^{1} \mathrm{O}_{2}$ 


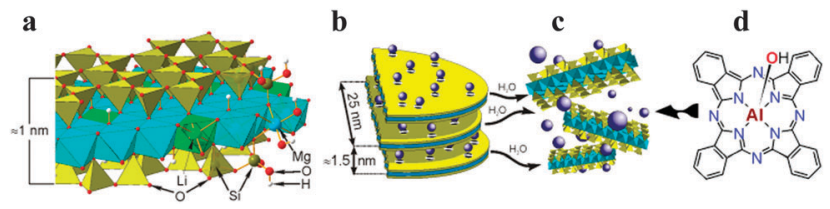

Fig. 1 Composition of LAPONITE ${ }^{\mathbb{R}}$ (a) and the dimensions of the disks (b), the solubility behavior (c) and adsorption of a dye (d), here demonstrated with $\mathrm{Al}(\mathrm{OH}) \mathrm{Pc}$.

generation, we should further mention the work by Takagi and Inoue et al., who reported on photo-physical properties including electron and energy transfers in a series of publications, a recent paradigmatic example of which we would like to quote here. ${ }^{16}$ Aggregation control for e.g. tetra-cationic $\mathrm{Zn}$ porphyrins intercalated by closely related saponite clays, predominantly employed in layers and membranes, has been accomplished as well, facilitating fluorescence efficiencies in the percent regime (2-4\%). ${ }^{17}$

In the present study we tackle the solubility and aggregation bottleneck simultaneously by employing a nano-clay (LAP) and unsubstituted $\mathrm{Al}(\mathrm{OH}) \mathrm{Pc}$ to form a novel organic-inorganic hybrid $(\mathrm{Al}(\mathrm{OH}) \mathrm{Pc}-\mathrm{LAP})$ with remarkable solubility and photo-physical performance in water. As the photo-active component of the hybrid, $\mathrm{Al}(\mathrm{OH}) \mathrm{Pc}$ appeared as a particularly attractive choice due to its comparably high water solubility, ${ }^{18}$ high fluorescence efficiency $(38 \%, \mathrm{Al}(\mathrm{Cl}) \mathrm{Pc}, \mathrm{DMSO}){ }^{19}$ and high ${ }^{1} \mathrm{O}_{2}$ efficiency, ${ }^{20}$ and encouraging clinical PDT tests with sulfonated AlPcS (Photosens). ${ }^{21}$ Finally, the presence of the easily accessible Al-hydroxo group may serve as an anchor for subsequent chemistry.

From several methods and solvents tested, the materials could be obtained most readily and reproducibly by straightforward dissolution and separation cycles from acetone: $\mathrm{Al}(\mathrm{OH}) \mathrm{Pc}$ was first extracted and filtered over a glass frit, yielding a clear blue, scatterfree stock solution, the content of which was determined spectrophotometrically. For this purpose an indirect method was applied, in which the acetone from an aliquot of the stock solution was removed (vacuum, $65{ }^{\circ} \mathrm{C}$, overnight) and the remnant dissolved in known volumes of conc. $\mathrm{H}_{2} \mathrm{SO}_{4}$. The absorption spectra were evaluated against a calibration curve freshly obtained from the dissolution of solid $\mathrm{Al}(\mathrm{OH}) \mathrm{Pc}$ in $\mathrm{H}_{2} \mathrm{SO}_{4}$, thus enabling the re-calculation of the stock solution's $\mathrm{Al}(\mathrm{OH}) \mathrm{Pc}$ content and its extinction coefficient $\left(\varepsilon_{672}=2.84 \times 10^{5} \mathrm{~L} \mathrm{~mol}^{-1} \mathrm{~cm}^{-1}\right.$ in acetone; for more details see the ESI $\dagger$ ). The loading efficiency in this first step amounted to only $0.2 \%$.

Unfortunately, the data material on extinction coefficients of $\mathrm{Al}(\mathrm{OH}) \mathrm{Pc}$ is very sparse, most likely due to its very low solubility and the obscuring formation of agglomerates even in organic solvents, and spreads over a factor of 1.6 for the so-called Q-band at around $680 \mathrm{~nm}$, i.e. ranging from $1.8 \times 10^{5}$ (dichlorobenzene) ${ }^{22}$ to $2.63 \times 10^{5} \mathrm{~L} \mathrm{~mol}^{-1} \mathrm{~cm}^{-1},{ }^{18}$ and from $1.32 \times 10^{5}$ up to $1.6 \times$ $10^{5} \mathrm{~L} \mathrm{~mol}^{-1} \mathrm{~cm}^{-1}$ for $\mathrm{Al}(\mathrm{OH}) \mathrm{PcS}_{x}\left(\mathrm{~S}=-\mathrm{SO}_{3}{ }^{-}, x=1-4\right.$, buffered $\mathrm{H}_{2} \mathrm{O}$, ethanol). ${ }^{23}$ The data presented here on $\mathrm{Al}(\mathrm{OH}) \mathrm{Pc}\left(\varepsilon_{672}=2.84 \times\right.$ $10^{5} \mathrm{~L} \mathrm{~mol}^{-1} \mathrm{~cm}^{-1}$ ), which were also taken for subsequent estimates of the concentrations, agree fairly well with the data found for mentioned pure $\mathrm{Al}(\mathrm{OH}) \mathrm{Pc}$ in water-ethanol mixtures. ${ }^{18}$ Furthermore, it is noteworthy that the spectra eventually obtained by us

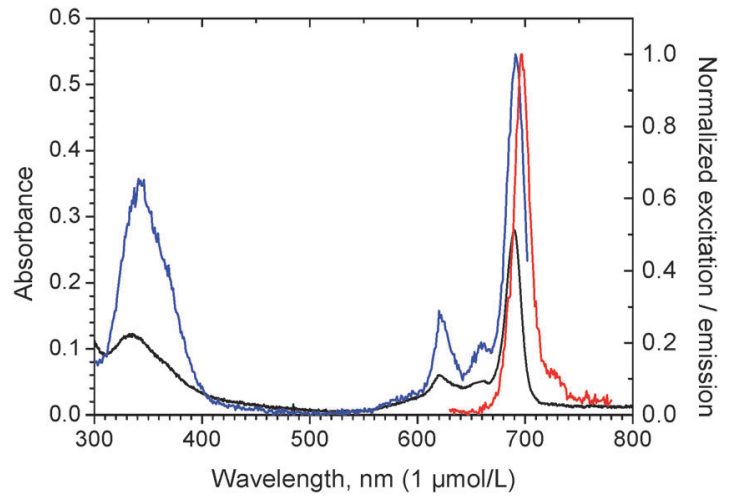

Fig. 2 Absorption (black), excitation ( $\lambda_{\mathrm{em}}=706 \mathrm{~nm}$, blue) and emission spectra $\left(\lambda_{\text {exc }}=620 \mathrm{~nm}\right.$, red) of Al(OH)Pc-LAP at $1 \mathrm{wt} \%($ LAP) at $1.063 \times$ $10^{-6} \mathrm{~mol} \mathrm{~L}^{-1}$ in water.

for low concentrations of $\mathrm{Al}(\mathrm{OH}) \mathrm{Pc}-\mathrm{LAP}$ hybrids in water (Fig. 2) perfectly match the monomer spectra thoroughly elaborated by Petrášek and Phillips ${ }^{23 b}$ in their investigation on the aggregation of sulfonated $\mathrm{Al}(\mathrm{OH}) \mathrm{PcS}_{x}$ in aqueous buffers at different $\mathrm{pH}$-values. We thus feel confident about the extinction coefficient found, although we have to concede that the photometrical determination may carry an appreciable experimental error (estimated to be $\pm 10 \%$ on the basis of a quadruple determination) due to the enormous magnitude of the extinction coefficient, and the corresponding difficulties in weighing out precise amounts.

In the subsequent second preparation step of the $\mathrm{Al}(\mathrm{OH}) \mathrm{Pc}-$ LAP hybrids, desired molar amounts of $\mathrm{Al}(\mathrm{OH}) \mathrm{Pc}$ were taken from the stock solution, added to untreated LAP powder, and diluted further to ensure a sufficient amount of solvent. After $24 \mathrm{~h}$ of stirring the powder was isolated by centrifugation from the now almost completely colourless acetone, the remaining acetone having retained only $3.7 \%$ of the original $\mathrm{Al}(\mathrm{OH}) \mathrm{Pc}$. After mildly drying the isolated solid $\mathrm{Al}(\mathrm{OH}) \mathrm{Pc}$ hybrids (vacuum chamber, $60{ }^{\circ} \mathrm{C}, 24 \mathrm{~h}$ ), the powders carrying between $3.850 \times 10^{-8}$ and $9.63 \times 10^{-7} \mathrm{~mol} \mathrm{Al}(\mathrm{OH}) \mathrm{Pc}$ per gram of nanoclay (nominal loads $\mathrm{Al}(\mathrm{OH}) \mathrm{Pc} / \mathrm{g} \mathrm{LAP}$ as obtained from dilution of the stock solution, see also Scheme S1, ESI $\dagger$ ) were redispersed in $\mathrm{H}_{2} \mathrm{O}$ so as to yield solutions containing $1 \mathrm{wt} \%$ with regard to LAP with a blue tint. Beyond a value of approximately one $\mu \mathrm{mol} \mathrm{L} \mathrm{L}^{-1}$, the solutions became slightly turbid and were discarded, except in those cases where the addition of $\beta$-diketonate co-ligands were employed to re-establish transparency (see below).

Even in solutions with concentrations as low as approximately $5 \times 10^{-7} \mathrm{~mol} \mathrm{~L}^{-1}$, we already observed an onset of dimer or oligomer formation (see the absorption spectra of the complete series in Fig. S2, ESI $\dagger$ ) with notably smaller extinction coefficients. $^{23 b}$ This strongly resembles the situation previously encountered for aqueous CuPc-LAP hybrids, ${ }^{12 d}$ which despite the unambiguous presence of dimers or oligomers $(\alpha$-CuPc) remained completely clear. For the $\mathrm{Al}(\mathrm{OH}) \mathrm{Pc}-\mathrm{LAP}$ too, the solutions retained their transparency in the visible region, i.e. showed no visually detectable turbidity, which has to be ascribed to the persistence of strong LAP interactions with the small $\mathrm{Al}(\mathrm{OH}) \mathrm{Pc}$ aggregates. Therefore, attention has to be paid to the validity of 


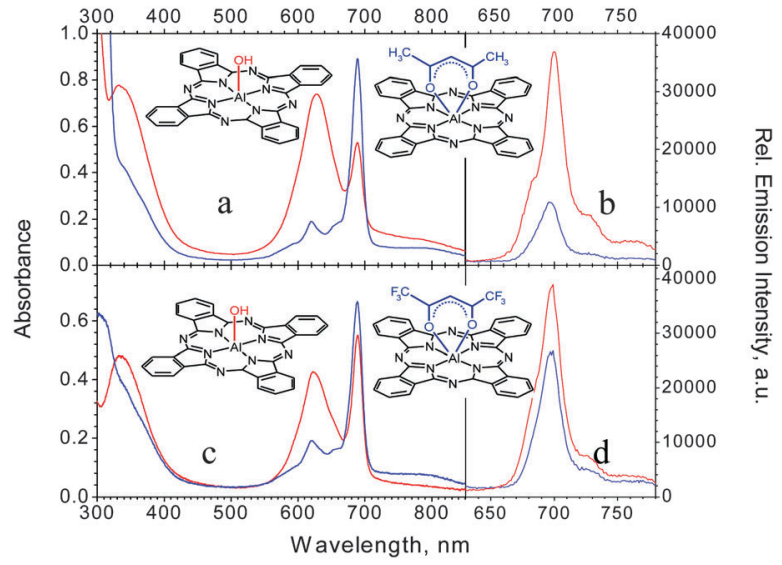

Fig. 3 Effect of addition of diketonates (blue lines) to Al(OH)Pc-LAP hybrids (red lines) in aqueous solutions. (a) Absorption spectra of Al(OH)Pc-LAP at $1 \mathrm{wt} \% \mathrm{LAP}$ and $3.133 \times 10^{-6} \mathrm{~mol} \mathrm{~L}^{-1}$ (red) and Al(acac)Pc after addition of excess amounts of Hacac. (b) Emission spectra for the same concentrations as (a). (c) Absorption spectra of Al(OH)Pc-LAP at 1 wt\% LAP and $2.465 \times 10^{-6} \mathrm{~mol} \mathrm{~L}^{-1}$ (red) and Al(hfa)Pc (blue) after addition of excess amounts of Hhfa. (d) Emission spectra for the same concentrations as (c).

the extinction coefficient given for concentrations above approximately $5 \times 10^{-7} \mathrm{~mol} \mathrm{~L}^{-1}$; beyond this value, a weaker increase in absorptivity reflects increasing amounts of $\mathrm{Al}(\mathrm{OH}) \mathrm{Pc}$ residing on the nano-clay as dimers or higher aggregates. Dimers formed could, however, to a certain degree be re-dissolved by adding co-ligands (diketonates) to the $\mathrm{Al}(\mathrm{OH}) \mathrm{Pc}$, as demonstrated in Fig. 3, at the same time improving the singlet oxygen production rate (see below). Disregardful of slight uncertainties in the precise concentrations, the general trends regarding solubility and photophysical properties observed and reported here will be valid.

Next to the unprecedented presence of $\mu$-molar amounts of the monomer in native aqueous $\mathrm{Al}(\mathrm{OH}) \mathrm{Pc}$, we were furthermore surprised by the efficiency $\Phi_{\mathrm{F}}$ of its emission, which assumed values of more than $20 \%$ (see Table 1 , measured relative to zinc 2,9,16,23-tetra-tert-butyl-29H,31H-phthalocyanine, $\mathrm{ZnPc}\left({ }^{t} \mathrm{Bu}\right)_{4}$, with a fluorescence quantum yield of $33 \%$ in toluene ${ }^{24}$ ) and is obviously a consequence of the screening towards dimerization as brought

Table 1 Concentrations and efficiencies of the aqueous AIPC-LAP species employed in the investigations

\begin{tabular}{|c|c|c|c|}
\hline Compound & $\begin{array}{l}\text { Concentration, } \mathrm{mol} \mathrm{L}^{-1} \text {; } \\
\text { LAP }(1 \mathrm{wt} \%)\end{array}$ & $\Phi_{\mathrm{F}}^{a}$ & $\Phi_{\Delta}^{b}$ \\
\hline $\mathrm{Al}(\mathrm{OH}) \mathrm{Pc}$ & $\begin{array}{l}3.9 \times 10^{-8} \\
7.7 \times 10^{-7} \\
1.93 \times 10^{-7} \\
3.85 \times 10^{-7} \\
5.78 \times 10^{-7} \\
7.7 \times 10^{-7} \\
9.63 \times 10^{-7}\end{array}$ & $\begin{array}{l}0.03 \\
0.13 \\
0.22 \\
0.18 \\
0.19 \\
0.19 \\
0.05\end{array}$ & $\begin{array}{l}\text { n.d. } \\
\text { n.d. } \\
0.0030 \\
0.0025 \\
0.0032 \\
\text { n.d. } \\
0.0001\end{array}$ \\
\hline $\mathrm{Al}(\mathrm{acac}) \mathrm{Pc}$ & $3.133 \times 10^{-6}$ & 0.08 & 0.0045 \\
\hline $\mathrm{Al}(\mathrm{hfa}) \mathrm{Pc}$ & $2.465 \times 10^{-6}$ & 0.03 & 0.0052 \\
\hline
\end{tabular}

about by the nano-clay. In addition, we also tested the new hybrids for their capability of generating ${ }^{1} \mathrm{O}_{2}$. A direct spectroscopic measurement of ${ }^{1} \mathrm{O}_{2}$ concentrations in water by recording its phosphorescence at $1270 \mathrm{~nm}$ evaded our instrumental capabilities; however, we were able to directly detect its emission in $\mathrm{CDCl}_{3}$, after its carrier (completely insoluble in organic solvents) had been rendered somewhat hydrophobic by modification of the LAPONITE ${ }^{\circledR}$ rims with methyloctadecyldimethoxysilane $\left(\mathrm{C}_{21} \mathrm{H}_{46} \mathrm{O}_{2} \mathrm{Si}\right)$, which in turn allowed low-concentration dispersions stable enough to conduct the measurements (Fig. S4 of the ESI $\dagger$ ). For quantification we measured the ${ }^{1} \mathrm{O}_{2}$ evolution in an indirect fashion using a procedure already described elsewhere. ${ }^{9 c, 25}$ In brief, the samples contained in $1 \mathrm{~cm}$ cuvettes were irradiated into their bottom using a $400 \mathrm{~W}$ halogen lamp using a $590 \mathrm{~nm}$ cut-off filter to select the red part of the spectrum, giving a measured irradiance of $8 \mathrm{~mW} \mathrm{~cm} \mathrm{~cm}^{-2}$. 9,10-Anthracenediyl-bis(methylene)dimalonic acid (ABMDMA) was used as a luminescent monitor, which readily reacts with ${ }^{1} \mathrm{O}_{2}$ to yield a non-luminescent anthracene endo-peroxide, i.e. photobleaching of the ABMDMA emission signal is quantitatively correlated with the amount of photocatalytically generated ${ }^{1} \mathrm{O}_{2}$. Efficiency data and singlet oxygen were determined against methylene blue (photosensitised ${ }^{1} \mathrm{O}_{2}$ quantum yield $\Phi_{\Delta}=0.52$ in water ${ }^{26}$ ); the concentrations of all samples, including methylene blue, were adjusted by dilution with water to give an absorbance of 0.1 (corresponding to $3.5 \times 10^{-7} \mathrm{~mol} \mathrm{~L}^{-1}$ ), at which the formation of dimers and higher associates appears to be suppressed. ${ }^{1} \mathrm{O}_{2}$ efficiencies of $0.3 \%$ could be established for the aqueous $\mathrm{Al}(\mathrm{OH}) \mathrm{Pc}-\mathrm{LAP}$ hybrid in this series, which have, to the best of our knowledge, not been observed before from native $\mathrm{Al}(\mathrm{OH}) \mathrm{Pc}$ or other unsubstituted, aqueous phthalocyanines. Untypically, however, the ${ }^{1} \mathrm{O}_{2}$ efficiencies remain low in view of the high fluorescence quantum yields, an issue deserving to be unravelled in more depth. LAPONITE ${ }^{\circledR} \mathrm{s}$ at their natural $\mathrm{pH}$ (10.1) exhibit a strongly negative surface charge, giving rise to mutual repulsion between their faces and the tetra-anionic ABMDMA monitor, which intuitively makes it less likely for the monitor to sense ${ }^{1} \mathrm{O}_{2}$ generated at the nano-clay surface. By the same token and in support of this view, methylene blue, which adheres very strongly due to its cationic nature, now also exhibits a low ${ }^{1} \mathrm{O}_{2}$ efficiency of only $0.2 \%$ due to the hindered access of ABMDMA. Although we found no immediate evidence for such in X-ray powder diffraction, the access of oxygen and the monitor to the nano-clay guest may additionally be restricted by sandwiching of LAP platelets.

However, the slower evolution of ${ }^{1} \mathrm{O}_{2}$ does not seem to prevent the usability for PACT, or may even be advantageous kinetically: even at low irradiation power (8 $\mathrm{mW}$ with a $680 \mathrm{~nm}$ LED) we preliminarily found killing rates of (Leerzeichen zuviel) $>99 \%$ for Gram positive bacteria (Staphylococcus aureus and Kocuria palustris, see the $\mathrm{ESI} \dagger$ for details).

In consecutive preparative attempts, polar solvents and additives were applied to the hybrid in the expectation that $\mathrm{CH}_{3} \mathrm{CN}$, DMSO, or polyethylene glycols would by virtue of co-adsorption remove water from the immediate environment of the $\mathrm{Al}(\mathrm{OH}) \mathrm{Pc}$ and enable further efficiency improvements. However, neither these nor quaternary ammonium ions (CTAB) or choline for example, which has recently been found to dramatically increase dye-LAP luminescence efficiencies, ${ }^{12 c}$ afforded noticeable improvements. Last but not least, 
we manipulated the Al-hydroxy-group of the $\mathrm{Al}(\mathrm{OH}) \mathrm{Pc}$ by anchoring chelating anionic ligands, the rationale being its replacement in order to prevent deactivation via high frequency vibrations of the -OH group; among others, chelators tested were acetylacetone (Hacac) and hexafluoracetylacetone (Hhfa).

In these samples, it was possible to set the concentrations 2 to 3 times higher than in the absence of the diketonates (see also Table 1 and Fig. 3) without turbidity or scattering, despite the obvious presence of dimers or aggregates, which are causing the very pronounced and broadened absorption at $628 \mathrm{~nm}$ with a shoulder extending towards the blue (H-dimers ${ }^{27}$ ) and a broad absorption feature above $730 \mathrm{~nm}\left(\mathrm{~J}\right.$-dimers $\left.{ }^{28}\right)$. While the fluorescence yields of the compounds remained moderate at high concentrations $(<10 \%)$, they nevertheless afforded the highest ${ }^{1} \mathrm{O}_{2}$ generation rates $\Phi_{\Delta}$ observed this far ( $0.4 \%$ and $0.5 \%$, respectively), albeit it should be recalled that they too were measured at notably lower concentrations. The reduction of the singlet emission quantum yields as compared to the previous series is clearly attributable to the relatively high concentrations, which give rise to substantial selfabsorption. Förster energy transfer may also contribute, if the nanoclay assembles $\mathrm{Al}(\mathrm{OH}) \mathrm{Pcs}$ within the critical Pc-Pc transfer distance of about $6.7 \mathrm{~nm} .{ }^{23 b}$ It will be of interest in the future, how the triplet state population rates, i.e. the singlet oxygen quantum yields eventually, are affected by such Homo-FRETs and re-absorption processes. As the present total "quantum turnover" (emitted photons + ${ }^{1} \mathrm{O}_{2}$ /absorbed photons), amounting to less than $25 \%$ at best, is still far from being optimal, challenging room is left for further investigations and improvements in this new type of the water based hybrid concept.

Overall, we perceive the findings on the predominance of monomeric Pc species in water along with the unprecedented, high fluorescence efficiencies and the capability for singlet oxygen generation as an urgent invitation to expose the novel hybrids to photocatalytic applications, with a focus on optimising their cytotoxicity for killing harmful bacteria like MRSA, and malignant cells for PDT, eventually. Next to the uses of $\mathrm{Al}(\mathrm{OH}) \mathrm{Pc}$ described here, we should concludingly remark that $\mathrm{Si}(\mathrm{OH})_{2} \mathrm{Pcs}$ appear to be just as suitable to form soluble hybrids with LAPONITE ${ }^{\circledR} \mathrm{s}$, which will open additional degrees of freedom in the design of carefully targeted hybrids.

\section{Notes and references}

$\S$ LAPONITE $^{\circledR}$, is a former trademark of Rockwood Additives Limited, now distributed by Altana/BYK. The term "LAPONITE ${ }^{\circledR}$ " is used synonymously in this text for LAPONITE ${ }^{\mathbb{R}} \mathrm{RD}$.

1 G. Löbbert, Ullmann's Encyclopedia of Industrial Chemistry, Wiley-VCH Verlag GmbH \& Co. KGaA, 2000.

2 F. H. Figge, G. S. Weiland and L. O. Manganiello, Anat. Rec., 1948, 101, 657.

3 M. C. DeRosa and R. J. Crutchley, Coord. Chem. Rev., 2002, 233-234, 351.

4 (a) A. Juzeniene, Q. Peng and J. Moan, Photochem. Photobiol. Sci., 2007, 6, 1234; (b) J. F. Lovell, T. W. B. Liu, J. Chen and G. Zheng, Chem. Rev., 2010, 110, 2839; (c) K. Ishii, Coord. Chem. Rev., 2012, 256, 1556; (d) N. Sekkat, H. v. d. Bergh, T. Nyokong and N. Lange, Molecules, 2011, 17, 98; (e) D. L. Ledson and M. V. Twigg, Inorg. Chim. Acta, 1975, 13, 43.
5 (a) M. Wainwright, J. Antimicrob. Chemother., 1998, 42, 13; (b) G. Jori, C. Fabris, M. Soncin, S. Ferro, O. Coppellotti, D. Dei, L. Fantetti, G. Chiti and G. Roncucci, Lasers Surg. Med., 2006, 38, 468; (c) T. Dai, Y.-Y. Huang and M. R. Hamblin, Photodiagn. Photodyn. Ther., 2009, 6, 170; (d) Z. Chen, S. Zhou, J. Chen, L. Li, P. Hu, S. Chen and M. Huang, J. Lumin., 2014, 152, 103.

6 (a) V. Mantareva, I. Angelov, V. Kussovski, R. Dimitrov, L. Lapok and D. Wöhrle, Eur. J. Med. Chem., 2011, 46, 4430; (b) V. Mantareva, V. Kussovski, I. Angelov, D. Wohrle, R. Dimitrov, E. Popova and S. Dimitrov, Photochem. Photobiol. Sci., 2011, 10, 91.

7 (a) S. Tuncel, F. Dumoulin, J. Gailer, M. Sooriyaarachchi, D. Atilla, M. Durmus, D. Bouchu, H. Savoie, R. W. Boyle and V. Ahsen, Dalton Trans., 2011, 40, 4067; (b) T. P. Mthethwa, Y. Arslanoglu, E. Antunes and T. Nyokong, Polyhedron, 2012, 38, 169.

8 X.-S. Li, M.-R. Ke, M.-F. Zhang, Q.-Q. Tang, B.-Y. Zheng and J.-D. Huang, Chem. Commun., 2015, 51, 4704.

9 (a) G. Obaid, I. Chambrier, M. J. Cook and D. A. Russell, Photochem. Photobiol. Sci., 2015, 14, 737; (b) M. Camerin, M. Magaraggia, M. Soncin, G. Jori, M. Moreno, I. Chambrier, M. J. Cook and D. A. Russell, Eur. J. Cancer, 2010, 46, 1910; (c) J. Voskuhl, U. Kauscher, M. Gruener, H. Frisch, B. Wibbeling, C. A. Strassert and B. J. Ravoo, Soft Matter, 2013, 9, 2453; (d) C. A. Strassert, M. Otter, R. Q. Albuquerque, A. Höne, Y. Vida, B. Maier and L. De Cola, Angew. Chem., Int. Ed., 2009, 48, 7928; (e) G. Obaid, I. Chambrier, M. J. Cook and D. A. Russell, Angew. Chem., 2012, 124, 6262; $(f)$ G. SchulzEkloff, D. Wöhrle, V. Iliev, E. Ignatzek and A. Andreev, in Stud. Surf. Sci. Catal., ed. H. G. Karge and J. Weitkamp, Elsevier, 1989, pp. 315-325.

10 T. Mthethwa and T. Nyokong, J. Lumin., 2015, 157, 207.

11 (a) R. Liang, R. Tian, L. Ma, L. Zhang, Y. Hu, J. Wang, M. Wei, D. Yan, D. G. Evans and X. Duan, Adv. Funct. Mater., 2014, 24, 3144; (b) X.-S. Li, M.-R. Ke, W. Huang, C.-H. Ye and J.-D. Huang, Chem.Eur. J., 2015, 21, 3310.

12 (a) M. M. Lezhnina, T. Grewe, H. Stoehr and U. Kynast, Angew. Chem., Int. Ed., 2012, 51, 10652; (b) T. Felbeck, T. Behnke, K. Hoffmann, M. Grabolle, M. M. Lezhnina, U. H. Kynast and U. Resch-Genger, Langmuir, 2013, 29, 11489; (c) T. Felbeck, S. Mundinger, M. M. Lezhnina, M. C. Staniford, U. Resch-Genger and U. H. Kynast, Chem. - Eur. J., 2015, 21, 7582; (d) M. C. Staniford, M. M. Lezhnina and U. H. Kynast, RSC Adv., 2015, 5, 3974.

13 BYK Additives\&Instruments, LAPONITE ${ }^{\circledR}$ - Performance Additives, Technical brochures on http://www.byk.com/, 29.01.2015.

14 E. Balnois, S. Durand-Vidal and P. Levitz, Langmuir, 2003, 19, 6633. 15 B. Ruzicka and E. Zaccarelli, Soft Matter, 2011, 7, 1268.

16 S. Konno, T. Fujimura, Y. Otani, T. Shimada, H. Inoue and S. Takagi, J. Phys. Chem. C, 2014, 118, 20504.

17 T. Fujimura, T. Shimada, S. Hamatani, S. Onodera, R. Sasai, H. Inoue and S. Takagi, Langmuir, 2013, 29, 5060.

18 T. M. Tsubone, G. Braga, B. H. Vilsinski, A. P. Gerola, N. Hioka, A. L. Tessaro and W. Caetano, J. Braz. Chem. Soc., 2014, 25, 890.

19 H. Yanık, D. Aydın, M. Durmuş and V. Ahsen, J. Photochem. Photobiol., A, 2009, 206, 18.

20 R. W. Redmond and J. N. Gamlin, Photochem. Photobiol., 1999, 70, 391. 21 (a) O. I. Apolikhin, I. V. Chernishov, A. V. Sivkov, D. V. Altunin, S. G. Kuzmin and G. N. Vorozhtsov, Proc. SPIE, 2007, 6632, 663213; (b) O. I. Trushina, E. G. Novikova, V. V. Sokolov, E. V. Filonenko, V. I. Chissov and G. N. Vorozhtsov, Photodiagn. Photodyn. Ther., 2008, 5, 256.

22 V. E. Pyatosin and M. P. Tsvirko, Zh. Prikl. Spektrosk., 1980, 33, 320. 23 (a) K. Palewska, M. Sujka, B. Urasińska-Wójcik, J. Sworakowski, J. Lipiński, S. Nešpůrek, J. Rakušan and M. Karásková, J. Photochem. Photobiol., A, 2008, 197, 1; (b) Z. Petrasek and D. Phillips, Photochem. Photobiol. Sci., 2003, 2, 236.

24 D. A. Fernández, J. Awruch and L. E. Dicelio, Photochem. Photobiol., 1996, 63, 784.

25 N. A. Kuznetsova, N. S. Gretsova, O. A. Yuzhakova, V. M. Negrimovskii, O. L. Kaliya and E. A. Luk'yanets, Russ. J. Gen. Chem., 2001, 71, 36.

26 F. Wilkinson, W. P. Helman and A. B. Ross, J. Phys. Chem. Ref. Data, 1993, 22, 113.

27 (a) W. J. Schutte, M. Sluyters-Rehbach and J. H. Sluyters, J. Phys. Chem., 1993, 97, 6069; (b) C. A. Strassert, M. E. Rodriguez, L. E. Dicelio and J. Awruch, J. Porphyrins Phthalocyanines, 2005, 09, 361.

28 T. Doane, A. Chomas, S. Srinivasan and C. Burda, Chem. - Eur. J., 2014, 20, 8030. 